\title{
COMPARISON OF PHYSICAL AND RHEOLOGICAL PROPERTIES OF PLAIN AND CRUMB RUBBER MODIFIED BITUMEN
}

\author{
Ramprasad.D.S ${ }^{1}$, Umesha.T.S ${ }^{2}$, Dinesh.S.V ${ }^{3}$, Dattatreya.J.K ${ }^{4}$ \\ ${ }^{1}$ Post Graduate Student, ${ }^{2}$ Associate Professor, ${ }^{3}$ Professor and Head, ${ }^{4}$ Research Professor, \\ Dept of Civil Engg, Siddaganga Institute of Technology, Tumkur \\ ramprasad6329@gmail.com,t_s_umesha@yahoo.co.in,dineshsv2004@yahoo.com,jk.dattatreya@gmail.com
}

\begin{abstract}
Bitumen is predominantly used to construct pavements for roads, highways, and airports. Due to the viscoelasticity nature of bitumen, it plays a predominant role in the performance of the pavements where temperature and rate of load application have a great influence. In India, the specifications for bituminous binders rely on different empirical tests which have almost no significance on their performance characteristics are reported. In this paper, the physical and rheological properties of bituminous binders commonly used in India, at high and intermediate field temperatures are reported in terms of their performance characteristics. Considering several factors that affect the behavior of bituminous binders, the effects of variations in temperature, rate of loading and amount of loading are considered. The changes in the properties of commonly used grades of (60-70) bitumen both unmodified and modified with crumb rubber have been reported. The Marshall properties and indirect tensile strength ratio are compared for the specimens prepared at optimum binder content $(O B C)$ for bituminous concrete $(B C)$ grading-2. Crumb rubber modified bitumen shows higher Marshall Stability, reduced flow, higher ITS ratio and improved rheological properties in terms of rutting.
\end{abstract}

Keywords: CRMB - crumb rubber modified bitumen, ITS- Indirect tensile strength, TFOT - Thin Film Oven test, DSR-

Dynamic shear rheometer MSCR- multiple shear creep recovery.

\section{INTRODUCTION}

Bituminous roads are the major part of network in India. The high intensity of traffic in terms of commercial vehicles and the over loading of trucks have been responsible for early development of distress symptoms like undulations, rutting, cracking and potholing of pavement. The factors, which are of serious concern, are the varying climatic conditions prevalent in India and the inadequate quality control during the construction of the roads. A flexible pavement structure is a sensitive system whose conditions change progressively as a result of the effects of traffic and the natural environment, rate of loading and number of repetition of loads. Due to increased loads and high temperature differential which are typical for Indian condition the conventional bitumen fails to give longer life for pavements. Addition of modifiers into conventional bitumen results in the improvement of performance characteristics of bituminous mixes used in road construction. The principle modes of failure of bituminous courses are fatigue and rutting which are influenced by temperature. Bitumen being a viscoelastic material, factors such as temperature, rate of loading and number of repetition of loads have a significant effect on the performance. Ageing of bitumen is a very complex process leading to hardening of bitumen. One of the major factor that cause pavements to crack and disintegrate is ageing phenomenon of bituminous binder (Aderson et al., 1994). Bituminous materials exhibit viscoelastic response and the performance of flexible pavements depends on the rate of loading and temperatures. The performance of bituminous binders can be measured by means of rheological parameters because the test can be done under wide range of temperatures and frequency (Goodrich ., 1998)

\section{EXPERIMENTAL PROGRAMME}

\subsection{Materials}

Two grades of modified bitumen (CRMB 55 and CRMB 60) and one grade of plain bitumen (60/70) supplied by HINCOL were used in the present investigation. Aggregates of size less than $19 \mathrm{~mm}$ were obtained from local quarry were used. Standard laboratory tests like penetration, ductility, softening point test were conducted for bitumen and Marshall stability and indirect tensile strength tests were conducted on the mixes prepared with both plain and crumb rubber modified bitumen. All rheological tests were conducted using dynamic shear rheometer for plain and modified binders (both short term aged and unaged). All the test results are interpreted in terms of MORTH and IRC recommendations. 


\subsection{Preparation of Test Specimen.}

\subsubsection{Preparation of Marshall Test Specimens}

Marshall Test specimens were prepared by adding $4 \%, 4.5 \%$, $5 \%, 5.5 \%, 6 \%$, and $6.5 \%$ of Bitumen. The specimen is compacted by giving 75 blows on both top and bottom side by keeping the temperature in the range of $110{ }^{\circ} \mathrm{C}-140{ }^{\circ} \mathrm{C}$. The compacted specimens were removed from moulds after 24 hours. The specimens were conditioned by keeping them in thermostatically controlled water bath maintained at $60^{\circ} \mathrm{C}$ for 30 minutes before testing.

\subsubsection{Preparation of Test Specimens for Rheological}

Tests.

A disk of binder with diameter equal to the ossilating plate of the DSR is needed for testing. About 10-20 g of binder at solid cosistancy is taken and placed in between the parallel plates of DSR.The thickness of the bitumen binder sandwiched between the spindle and the fixed plate must be carefully controlled by removing the excess material using knife. The proper specimen thickness $(1 \mathrm{~mm})$ is achieved by adjusting the gap between spindle and fixed plate using micrometer wheel.

\subsubsection{Thin film oven test (TFOT)}

Thin film oven test was conducted for plain and modified binders for determining the properties after short term ageing.

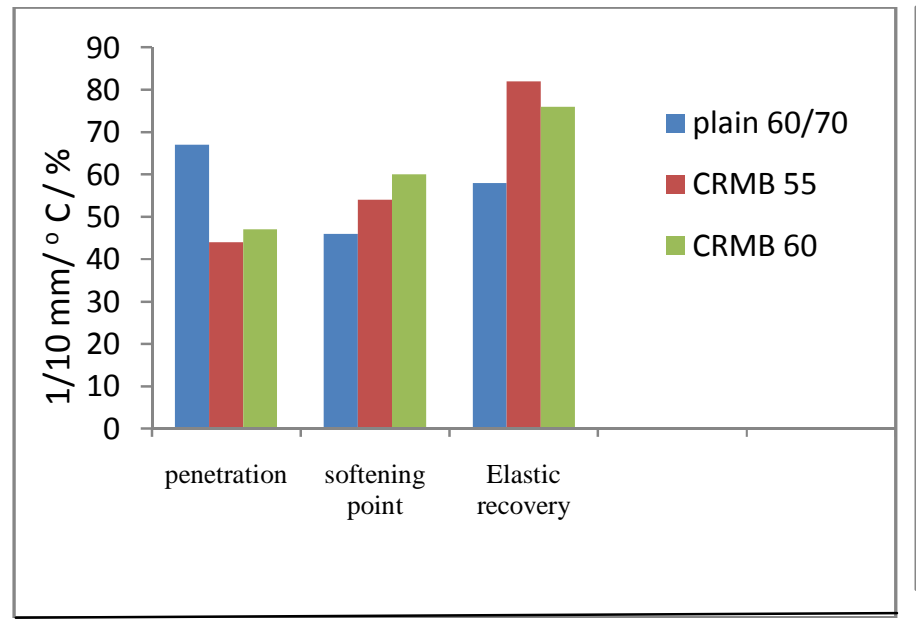

Fig 1: Properties of binder before short term ageing

It is observed from Fig 1 that the crumb rubber modified bitumen shows lower penetration, higher softening point and higher elastic recovery when compared to plain bitumen. From Fig 1 and 2 it is observed that crumb rubber shows better resistance to ageing compared to plain bitumen as evident from lower mass loss $(0.2 \%$ against $4.4 \%$ not reported here),small increase in softening point and small decrease in
Binder samples were placed in thin film oven apparatus for 5 hours at a constant temperature of $163^{\circ} \mathrm{C}$. This test simulates the hardening conditions as would be expected during hot mixing operations.

\section{RESULTS AND DISCUSSIONS}

Investigations are carried out on bituminous concrete (BC grading 2) mix with different types of binders viz, conventional bitumen (60/70), CRMB 55 and CRMB 60 to evaluate the mechanical properties such as Marshall stability, Indirect Tensile Strength (ITS) and rheological properties of both aged and unaged binder samples. The observations made on the results are presented and discussed in the following paragraphs.

\subsection{Physical Properties}

The basic tests such as softening point, penetration and elastic recovery conducted on plain bitumen are presented in Fig 1. After subjecting the binder sample to thin film oven test which simulates the short term ageing, the residue is tested for various physical properties such as softening point, penetration and elastic recovery. The results obtained are shown in Fig 2.

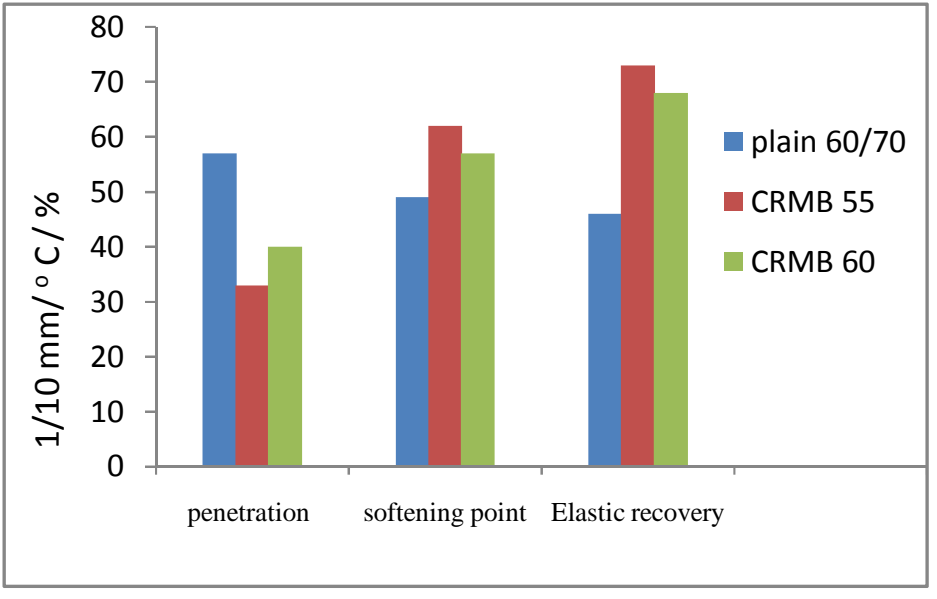

Fig 2: Properties of binder after short term ageing

penetration. This resistance to short term ageing is pronounced by reduced evaporation of volatiles in CRMB. The addition of crumb rubber results in hardening of bitumen, the grains of rubber absorbs some of the oily constituents in the bitumen. These grains swollen to about five times the volume are dispersed in the bitumen, which is then harder than, that of the same type as original (Van rooigen., 1941 ,White oak., 1990) 
Table 1 shows the Marshall properties in terms of various binders considered in the present study. It is observed from the Table 1 that Marshall oproperties confirms to the MORTH recommendations. CRMB 55 and CRMB 60 have higher stability and lower flow value compared to the plain bitumen. Optimum binder content was obtained corresponding to median of air voids percentage $(4.5 \%)$ the OBC for three different binder is 5,5.1,5.2 for plain, CRMB 55 and CRMB
60 respectively. Though the optimum binder content for CRMB is slightly higher than that of plain bitumen it shows higher strength in terms of increased Marshall stability and decreased flow value. The stability and flow value indicates increased life and service condition and thereby will result in reduced life cycle cost.

Table 1: Marshall Properties of the mixes for OBC of different binders

\begin{tabular}{||l||l||l|l|l|l|l||}
\hline Binder type & Gmb & \%VMA & $\%$ VFB & $\begin{array}{l}\text { Stability } \\
(\mathrm{kN})\end{array}$ & $\begin{array}{l}\text { Flow } \\
(\mathrm{mm})\end{array}$ & OBC \\
\hline \hline Plain 60/70 & 2.373 & 16.080 & 72 & 13.6 & 3.8 & 5 \\
\hline \hline CRMB 55 & 2.339 & 16.105 & 71 & 15.8 & 3.3 & 5.1 \\
\hline \hline CRMB 60 & 2.335 & 16.450 & 73 & 14.6 & 2.8 & 5.2 \\
\hline \hline $\begin{array}{l}\text { MORTH } \\
\text { specification }\end{array}$ & - & Min 14 & $65-75$ & Min 9 kN & $2-4$ & $5-7$ \\
\hline
\end{tabular}

Figure 3 shows the Results of indirect tensile strength ratio (ITS ratio), it is observed that there is a marginal increase in indirect tensile strength ratio for CRMB. The increase in indirect tensile strength ratio results in higher resistance to the damage associated with moisture.

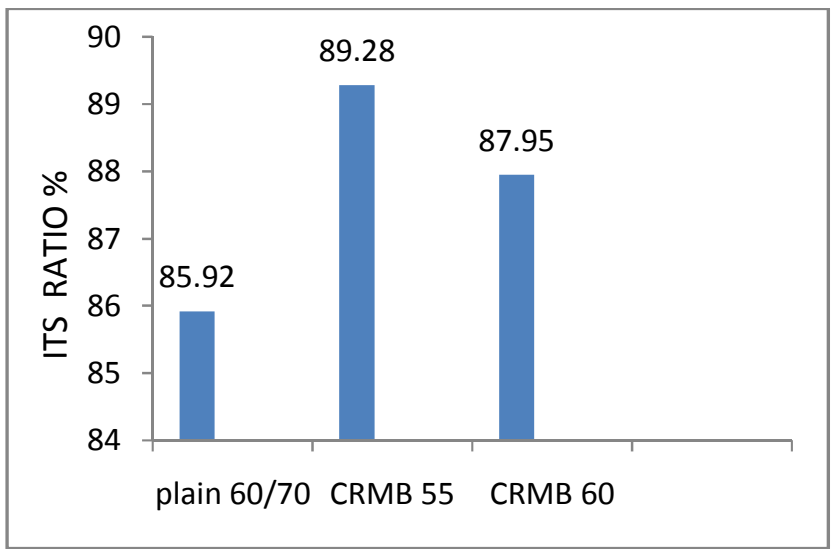

Fig3: Variation of Tensile Strength Ratio

Addition of crumb rubber resulted in increased indirect tensile strength ratio. Crumb rubber modified mixtures were found to be less susceptible to moisture damage compared to normal mixtures as indicated by higher retained Marshall Stability, higher tensile strength ratio and improved stripping characteristics (S. K. Palit.et.al., 2004)

\subsection{Rheological Test Results}

Figure 4 shows the variation of Complex Modulus with temperature, in general the complex modulus of plain bitumen is less when compared to CRMB 55 and CRMB 60. Among this CRMB 55 shows higher complex modulus with temperature. It is clearly observed from the Fig 4 that the plain bitumen fails (value of complex modulus less than $1 \mathrm{k} \mathrm{Pa}$ ) at temperature $64{ }^{\circ} \mathrm{C}$, but CRMB 55 and CRMB 60 are stable. But whereas CRMB 55 and CRMB 60 fails at $70{ }^{\circ} \mathrm{C}$ this clearly indicates that CRMB grades are less susceptible to temperature changes when compared to plain bitumen.

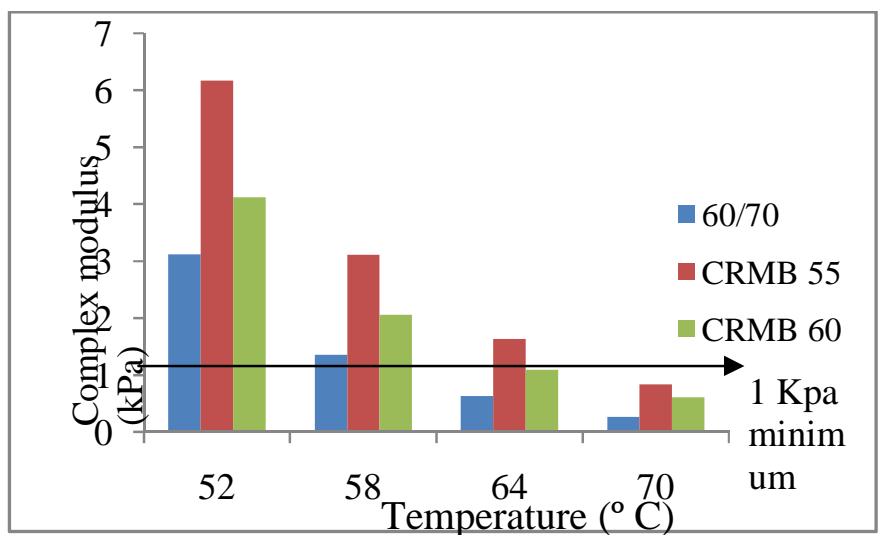

Fig 4: Variation of Complex Modulus with temperature 
Figure 5 shows the results of frequency sweep test, It is observed that, the general trend is that the complex shear modulus $\left(\mathrm{G}^{*}\right)$ increases with the testing frequency. CRMB 55 after ageing has higher complex modulus when compared to other binders. This indicates CRMB 55 possess greater strength.

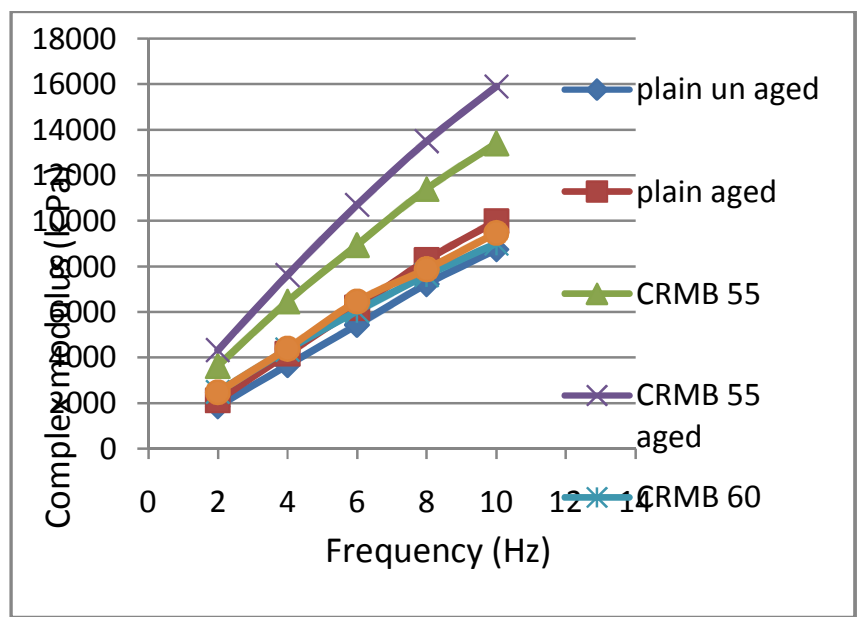

Fig 5: Complex modulus v/s Frequency

When the crumb rubber is added to the bitumen it cause the absorption of aromatic oils thereby softening and swelling of the rubber particles.. In conclusion, the addition of crumb rubber as modifier to the base bitumen produces stiff and tough bitumen. (Oliver et. al., 1982)

The TFOT materials were obviously much stiffer than the unaged samples over the entire range of frequencies which indicates that once the binder is aged the stiffness changes greatly with the frequency of loading. Hence it is concluded that as the binder is aged it becomes stiffer and more elastic. Ageing has significant influence on bitumen rheology by increasing complex modulus (Mohammed et. al., 2008).

Figure 6 shows the results of multiple shear creep recovery (MSCR) test, Plain bitumen shows higher non recoverable compliance when compared to modified bitumen. Higher the non recoverable compliance can possibly increase the magnitude of rutting in the actual service life. When rubber is added to base bitumen, the elastomer absorbs the maltene content thereby increasing the asphaltene content. This is why the CRMB is harder than the base bitumen and this leads to an increased resistance to pavement rutting. (Robert. et al 2000). Rubber content has the potential to resist rutting deformation that occurs in road pavement as result of increased traffic loading (Nuha et.al., 2012).

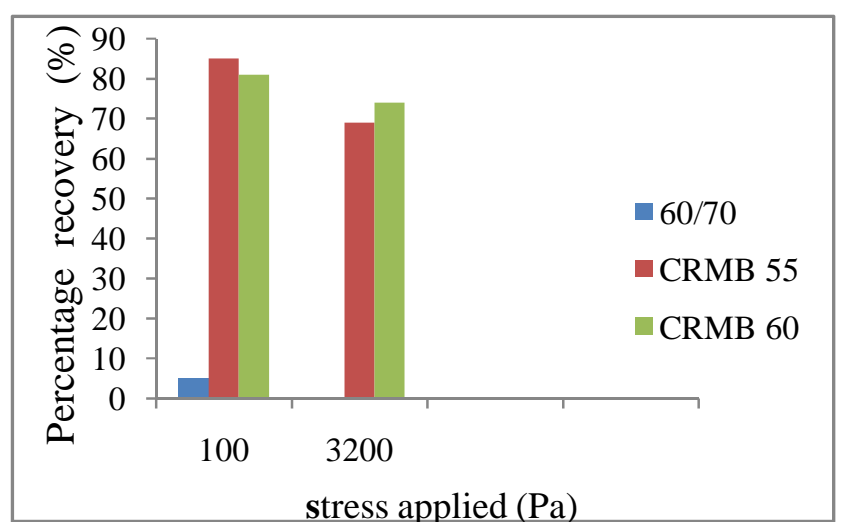

Fig 6: Variation of percentage recovery with applied stress

\section{CONCLUSIONS}

$>\quad$ The addition of crumb rubber to the bitumen results in the improvements in the basic properties like softening point, penetration and elastic recovery.

$>\quad$ The resistance to ageing of CRMB is more when compared to the plain bitumen because, evaporation of volatiles in case of CRMB is less.

$>\quad$ The increase in indirect tensile strength ratio is observed for the mixes prepared using CRMB.This results in higher resistance to the damage associated with moisture.

$>\quad$ The modified bitumen has higher complex modulus than plain bitumen which means that it is more stable. This means that using crumb rubber with plain bitumen increases the binder elasticity at high temperatures and improves the flexibility at low temperatures thereby lessening both rutting and fatigue cracking.

$>$ From MSCR tests, it is observed that, plain bitumen shows higher non recoverable compliance when compared to modified bitumen. Higher the non recoverable compliance can possibly increase the magnitude of rutting in the actual service.

\section{REFERENCES}

[1] Anderson. D.W. Christensen, H.U Bahia, R Dongre., (1994) "SHRP national research council".,

[2] Goodrich J.L., (1998) "Bitumen and polymer modified Bitumen properties related to the performance of Bitumen concrete mixes", Journal of the Association of Bitumen Pavement Technologists, Volume 57, pp.116160.

[3] White oak.C.D., (1990). "The Shell Bitumen Handbook". Shell Bitumen UK. Thomas Telford publishing. $5^{\text {th }}$ edition, London.

[4] J.M Van rooigen., (1941) " The system Bitumenic bitumen rubber powder" vol 33, No 6 rubber foundation, Holland 
[5] S. K. Palit, K. Sudhakar Reddy and B. B. Pandey., ASCE / january/february 2004 / 45."Laboratory Evaluation of Crumb Rubber Modified Bitumen Mixes" journal of materials in civil engineering.

[6] Oliver John WH., (1992). "Optimizing the improvements obtained by the digestion of comminuted scrap rubbers in paving asphalts". AAPT1983;51:16988.

[7] A.A Mohammed and Husaini Omar., (2008) "Rheological properties of crumb rubber modified bitumen containing antioxidant" the Arabian journal for science and engineering, volume 34, number 1B.

[8] Nuha S. Mashaan, Asim Hassan Ali, Mohamed Rehan Karim and Mahrez Abdelaziz., (2012)“An overview of crumb rubber modified Bitumen" International Journal of the Physical Sciences Vol. 7(2).

[9] Ministry of Road Transport and Highways Specification (2010)

[10] IRC SP: 53-2002, 2004, 2010 "Guidelines on use of Polymer and Crumb Rubber Modified binders. 